\title{
Cetyltrimethylammonium Bromide Silver Bromide Complex as the Capping Agent of Gold Nanorods
}

\author{
Fabien Hubert, Fabienne Testard, and Olivier Spalla* \\ IRAMIS-SCM-LIONS, CEA Saclay, 9191 Gif-sur-Yvette, France \\ Received June 3, 2008. Revised Manuscript Received July 7, 2008
}

\begin{abstract}
A complex between cetyltrimethylammonium bromide (CTAB) surfactant and silver bromide (CTASB) is recognized by NMR and X-ray photoelectron spectroscopy (XPS) to be the entity at the surface of gold nanorods, resulting from an in situ formation in the classical scheme of synthesis. It can thus be introduced directly along with the initial reactants in place of silver(I) salt to produce a new effective synthesis of these objects. Complementary XPS and quartz crystal microbalance (QCM) measurements on macroscopic gold surfaces confirm a strong adsorption of CTASB that is higher than that of CTAB and any other CTAX surfactants. The role of CTASB as a rod inducing agent by surface complexation is stressed.
\end{abstract}

\section{Introduction}

One dimensional metallic nanostructures have aroused great attention due to their future potential applications, expected mainly from their size-dependent optical properties ${ }^{1-3}$ or their use as building bricks in bottom-up approaches. ${ }^{4}$ Biological applications such as detection or gene delivery are other targets of interest. ${ }^{5}$ Electrochemical deposition in templates,${ }^{6}$ electrochemical synthesis in solution, ${ }^{7}$ photochemical synthesis, ${ }^{8}$ and the seedmediated growth approach ${ }^{9}$ are nonexhaustive examples of the numerous existing methods for the synthesis of gold nanorods. Wet chemical methods are the prefered routes due to the costeffective, large-scale production of nanorods, and among them the seed-mediated growth approach is particularly interesting due to the high nanorod yields that can be reached. Indeed, since the original work on seed-mediated synthesis of gold nanorods, ${ }^{9}$ extensive studies have been devoted to the increase of the yield, monodispersity, and stability of the particles. In fact, achieving control over the growth toward gold nanorods with high yields is a challenging task. High yields were reached through the use of silver nitrate salt along with the other additives. ${ }^{10}$ Shorter aspect ratio rods are obtained compared to those obtained without silver(I) nitrate. However, short aspect ratio rods are interesting in that they present both transverse and longitudinal intense plasmon bands in the visible region of the spectrum, making them promising candidates for sensing or imaging applications. ${ }^{11,12}$

Several sources have been advanced as the driving force for anisotropy. It has been suggested ${ }^{13}$ that the presence of surfactant

* To whom correspondence should be addressed. olivier.spalla@cea.fr.

(1) Daniel, M. C.; Astruc, D. Chem. Rev. 2004, 104, 293-346.

(2) Nikoobakht, B.; El-Sayed, M. A. J. Phys. Chem. A 2003, 107, 3372-3378.

(3) Xu, X.; Gibbons, T. H.; Cortie, M. B. Gold Bull. 2006, 39, 156-165.

(4) Obare, S.; Jana, N. R.; Murphy, C. J. Nano Lett. 2001, 1, 601-603.

(5) Bauer, L. A.; Birenbaum, N. S.; Meyer, G. J. J. Mater. Chem. 2004, 14 , $517-526$.

(6) Foss, C. A.; Hornyak, G. L.; Stockert, J. A.; Martin, C. R. J. Phys. Chem. 1992, 96, 7497-7499.

(7) Chang, S. S.; Shi, C. W.; Chen, C. D.; Lai, W. C.; Wang, C. R. C. Langmuir 1999, 15, 701-709.

(8) Kim, F.; Song, J. H.; Yang, P. J. Am. Chem. Soc. 2002, 124, 14316-14317.

(9) Jana, N. R.; Gearheart, L.; Murphy, C. J. J. Phys. Chem. B 2001, 105 , 4065-4067. 1393.

(10) Jana, N. R.; Gearheart, L.; Murphy, C. J. Adv. Mater. 2001, 13, 1389-

(11) Haynes, C. L.; Van Duyne, R. P. J. Phys. Chem. B 2001, 105, 5599-5611.

(12) Sönnichsen, C.; Franzl, T.; Wilk, T.; von Plessen, G.; Feldmann, J.; Wilson, O.; Mulvaney, P. Phys. Rev. Lett. 2002, 88, 1389-1393. bilayers around the nanorods promotes the development of anisotropy through a "zipping" process. Long chain surfactants, such as cetyltrimethylammonium bromide (CTAB), are indeed needed to ensure a high yield of nanorods with good anisotropic ratio, while short chain surfactants lead to a higher percent of spherical byproducts and/or shorter rods. ${ }^{14}$ The role of the surfactant counterion was also considered, ${ }^{15,16}$ concluding that only brominated long chain surfactants lead to significant yields of rod shaped particles. The final mandatory component to obtain high yield syntheses of rods is silver(I) nitrate. ${ }^{10}$ The most commonly cited role of silver(I) is a reaction with CTAB to form the silver bromide compound that would deposit onto some preferential gold rods' facets and thus hinder their growth in that direction. ${ }^{15}$ However, it has also been suggested that metallic silver deposits preferentially onto certain faces of the rod, due to the more positive underpotential of deposition of silver(I) on (110) facets, thus poisoning these facets. ${ }^{17}$

In this study, we propose an alternative mechanism based on spectroscopic characterizations of a seedless variation of the classical route of synthesis using silver nitrate. We recognize the primordial role of an in situ formed complex of CTAB and silver bromide hereafter named CTASB which can also be prepared ex-situ. ${ }^{18}$ Accordingly, an improved synthesis involving the use of CTASB as a cosurfactant along with CTAB and without silver nitrate is performed, which leads to a high yield nanorod synthesis for which the anisotropy promoter is specifically identified.

\section{Results and Discussion}

In a first stage, gold nanorods were prepared via a seedless synthesis inspired from Jana: ${ }^{19}$ a $10 \mathrm{~mL}$ solution containing 3.5 $\mathrm{mM}$ aqueous tetrachloroauric acid, 0.2 $\mathrm{M} \mathrm{CTAB}$, and $1 \mathrm{mM}$ silver nitrate was constituted. Next, $0.12 \mathrm{~mL}$ of $0.4 \mathrm{M}$ ascorbic acid was added under stirring. Finally, $64 \mu \mathrm{L}$ of an ice-cold aqueous $1.6 \mathrm{mM}$ sodium borohydride solution was added. The

(13) Nikoobakht, B.; El-Sayed, M. A. Langmuir 2001, 17, 6368-6374.

(14) Gao, J.; Bender, C. M.; Murphy, C. J. Langmuir 2003, 19, 9065-9070.

(15) Perez-Juste, J.; Pastoriza-Santos, I.; Liz Marzán, L. M.; Mulvaney, P. Coord. Chem. Rev. 2005, 249, 1870-1901.

(16) Kawasaki, H.; Nishimura, K.; Arakawa, R. J. Phys. Chem. C 2007, 111, 2683-2690.

(17) Liu, M.; Guyot-Sionnest, P. J. Phys. Chem. C 2005, 109, 22192-22200.

(18) Liu, X. H.; Luo, X. H.; Lu, S. X.; Zhang, J. C.; Cao, W. L. J. Colloid Interface Sci. 2007, 307, 94-100.

(19) Jana, N. R. Small 2005, 1, 875-882. 
Table 1. ${ }^{1} \mathrm{H}$ NMR Chemical Shits in $\mathbf{p p m}^{a}$

\begin{tabular}{lcccc}
\hline \multicolumn{1}{c}{ protons } & $\begin{array}{c}\text { capped gold } \\
\text { nanorods }\end{array}$ & CTASB & $\begin{array}{c}\text { capped gold } \\
\text { nanospheres }\end{array}$ & CTAB \\
\hline$\alpha-\mathrm{CH}_{2}$ & 3.31 & 3.32 & 3.38 & 3.44 \\
$\mathrm{~N}\left(\mathrm{CH}_{3}\right)_{3}$ & 3.12 & 3.12 & 3.15 & 3.19 \\
$\beta-\mathrm{CH}_{2}$ & 1.79 & 1.79 & 1.78 & 1.77 \\
$\mathrm{CH}_{2}$ main chain & 1.30 & 1.30 & 1.29 & 1.30 \\
$\mathrm{CH}_{3}$ main chain & 0.87 & 0.87 & 0.87 & 0.87 \\
$\mathrm{CH}_{2}$ main chain & does not appear & 1.37 & 1.37 & 1.37
\end{tabular}

${ }^{a}{ }^{1} \mathrm{H}$ NMR spectra in the Supporting Information. Values reported for capped nanorods stand the same for the two ways of synthesis (initial presence of silver nitrate or CTASB).

reaction, followed using UV-visible spectroscopy, was complete in less than $20 \mathrm{~min}$. Transmission electron microscopy (TEM) analysis of the final particles provides the extensive dimensions for the rods, that is, $\sim 9 \mathrm{~nm}$ in diameter for $32 \mathrm{~nm}$ in length, with $90 \%$ rods along with very few spherical byproducts. As a reference, gold nanospheres were also prepared by the same synthesis method as above but simply without addition of silver nitrate.

Detailed information about the interaction between the surfactant and gold nanorods can be obtained from NMR measurements. ${ }^{20}$ Table 1 presents the chemical shifts of the ${ }^{1} \mathrm{H}$ spectra for a $\mathrm{D}_{2} \mathrm{O}$ solution of $\mathrm{CTAB}$, as well as $\mathrm{D}_{2} \mathrm{O}$ solutions of capped gold nanospheres and capped gold nanorods, extracted from the initial surfactant solution and washed in heavy water. For all the protons of the main chain, except the $\alpha$ ones, the chemical shifts are identical for all three solutions. On the contrary, the chemical shifts of $\alpha-\mathrm{CH}_{2}$ and $\mathrm{N}-(\mathrm{CH} 3)_{3}$ for the capped gold nanorods, gold nanospheres, and CTAB are different. Indeed, chemical shifts go slightly highfield from CTAB to capped gold nanospheres, probably due to the vicinity of the gold surface to the head's protons (Knight shift ${ }^{21}$ ). As for capped gold nanorods, the chemical shifts are even lower, indicative of an additional or a different contribution to the chemical shifts other than that of the Knight shift.

A CTAB silver complex (CTASB) was recently identified ${ }^{18}$ in the mixture of CTAB and silver nitrate. Accordingly, the ${ }^{1} \mathrm{H}$ NMR chemical shifts of CTASB are presented in Table 1 . The chemical shifts for a solution of CTASB are indeed identical to the ones obtained for capped gold nanorods. The highfield chemical shifts for $\alpha-\mathrm{CH} 2$ and $\mathrm{N}-(\mathrm{CH} 3)_{3}$ protons as compared to solutions of CTAB and CTAB capped gold nanospheres can now be attributed to the presence of a silver atom near to the $\mathrm{N}$-polar head protons. This influence is complementary to the simple Knight shift of gold observed on capped gold nanospheres. An enlargement of the peaks for capped nanorods protons from the headgroup is also observed, further supporting the surfactants' binding to the gold surface by their headgroup.

The preceding results suggest that CTASB, a stable complex formed in situ, could be the real promoter of the anisotropy of the nanoparticles. In order to confirm this hypothesis, a new synthesis scheme was designed. CTASB was first prepared ex situ as in ref 18 . Its purity was checked by $\mathrm{X}$-ray diffraction (XRD) and elemental analysis, providing its formula $\mathrm{C}_{19} \mathrm{H}_{42-}$ $\mathrm{NAgBr}_{2}$. A $10 \mathrm{~mL}$ solution containing $3.5 \mathrm{mM}$ aqueous tetrachloroauric acid, 0.2 M CTAB, and various concentrations (from 0.2 to $2 \mathrm{mM}$ ) of CTASB was then constituted. Next, to each solution, $0.12 \mathrm{~mL}$ of $0.4 \mathrm{M}$ ascorbic acid was added under stirring. Finally, $64 \mu \mathrm{L}$ of an ice-cold aqueous $1.6 \mathrm{mM}$

(20) Terrill, R. H.; Postlethwaite, T. A.; Chen, C.; Poon, C.; Terzis, A.; Chen, A.; Hutchison, J. E.; Clark, M. R.; Wignall, G.; Londono, J. D.; Superfine, R.; Falvo, M.; Johnson, C. S., Jr.; Samulski, E. T.; Murray, R. W. J. Am. Chem. Soc. 1995, 117, 12537-12548.

(21) Knight, W. D. Phys. Rev. 1949, 76, 1259-1260.

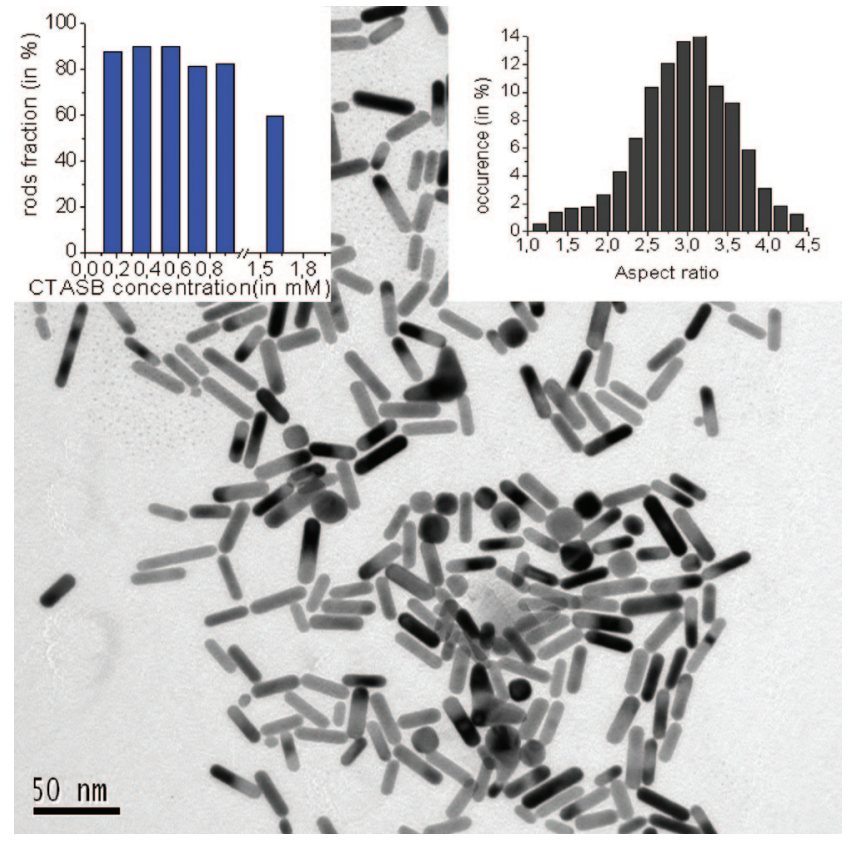

Figure 1. TEM picture of rods obtained with $[\mathrm{CTASB}]=0.55 \mathrm{mM}$. Right inset: aspect ratio distribution from TEM images analysis. Left inset: rod fraction (percentage in number of objects) as a function of the CTASB initial concentration from TEM image analysis.

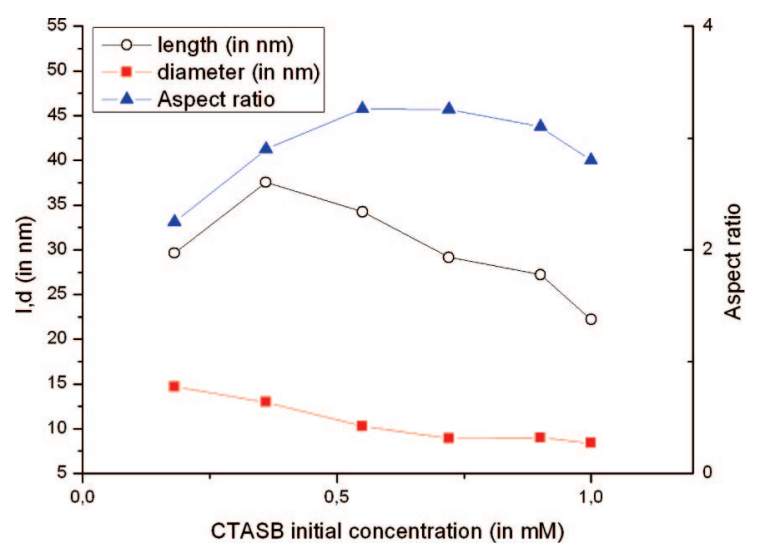

Figure 2. Dimensions of the gold nanorods as a function of the CTASB initial concentration.

sodium borohydride solution was added. This new scheme does not make use of silver(I) nitrate or another $\mathrm{Ag}^{+}$salt.

Using $\mathrm{UV}-$ visible measurements, the reaction was again followed for each CTASB concentration. The reaction is still complete in less than 20 min and provides nanorods. The XRD pattern of the gold nanorods shows that the particles are crystalline. Peaks are consistent with the bulk face-centered cubic (fcc) pure gold crystal. The respective intensities for the [111], [200], [220], and [311] peaks differ from the theoretical ones for bulk gold, indicating the preferential orientation along [111] and [100] planes in the gold nanorods and more to the point, among the two of them, the predominance of the [111] faces, that is, the side ones of the rods. The aspect ratio of the final particles, extracted from TEM analysis, reaches a maximum of 3.2 for $0.55 \mathrm{mM} \mathrm{CTASB}$ (Figure 1). A decrease in CTASB concentration leads to less anisotropic rods and an increase, to similar aspect ratios (ranging from 3.2 to 2.8) (Figure 2), but with the presence of more spheres (40\% for $1.6 \mathrm{mM} \mathrm{CTASB),} \mathrm{as} \mathrm{seen} \mathrm{in} \mathrm{the} \mathrm{left} \mathrm{inset} \mathrm{in} \mathrm{Figure}$ 1. The evolution in the aspect ratios is confirmed by UV-visible measurements, though, as stated in ref 22 , the estimated value 
Table 2. XPS Binding Energies in $\mathrm{eV}^{a}$

\begin{tabular}{lccccc}
\hline element & $\begin{array}{c}\text { capped gold } \\
\text { nanorods }\end{array}$ & CTASB & $\begin{array}{c}\text { capped gold } \\
\text { nanospheres }\end{array}$ & CTAB & AgBr sol \\
\hline $\mathrm{Au} \mathrm{4f_{7/2 }}$ & 84.0 & & 84.0 & & \\
$\mathrm{Au} \mathrm{4f_{5/2 }}$ & 87.7 & & 87.7 & & \\
$\mathrm{Ag} \mathrm{3d} \mathrm{d}_{5 / 2}$ & 367.7 & $367.7^{18}$ & & & $367.7^{27}$ \\
$\mathrm{Ag} \mathrm{3d}$ & 373.7 & $373.8^{18}$ & & & $373.7^{27}$ \\
$\mathrm{Br} \mathrm{3d} 5 / 2$ & 67.8 & $67.9^{18}$ & 67.7 & $67.3^{25}$ & $68.3^{27}$ \\
& & & & $67.5^{26}$ & \\
$\mathrm{~N} \mathrm{1s}$ & $402.4(5)$ & $402.3^{18}$ & $402.1(5)$ & $402^{24}$ & \\
& & $402.4^{b}$ & & $402.1^{b}$ &
\end{tabular}

${ }^{a}$ Nanorod $\mathrm{Br} 3 \mathrm{~d}, \mathrm{~N}$ 1s, and $\mathrm{Ag} 3 \mathrm{~d}$ XPS spectra in the Supporting Information. Values for nanorod synthesis in the presence of silver nitrate and CTASB stand the same. ${ }^{b}$ This work.

is slightly different from the one obtained by TEM. According to TEM analysis, the highest rod length is reached for $0.4 \mathrm{mM}$ CTASB, while for higher concentrations it decreases, from 37.5 to $22.5 \mathrm{~nm}$ (Figure 2). On the other hand, the diameter of the rods constantly decreases with an increase in CTASB, from 15 to $8 \mathrm{~nm}$, suggesting the idea of a surface poisoning by CTASB. In conclusion, the optimum CTASB concentration is $0.55 \mathrm{mM}$, with more than $90 \%$ rods along with few spherical and cubical byproducts.

It was checked that the NMR spectrum of the extracted particles is the same as the one for the $\mathrm{CTAB} /$ silver nitrate synthesis.

In order to further characterize the CTASB species on the surface of the nanorods, X-ray photoelectron spectroscopy (XPS) measurements were conducted, on both CTAB/CTASB and $\mathrm{CTAB} / \mathrm{AgNO}_{3}$ nanorod syntheses as well as on pure CTASB. Several drops of the extracted nanoparticle solutions or a CTASB solution were deposited on a silicon wafer, dried under nitrogen, and then inserted in the XPS chamber. The XPS spectrum for gold nanorods showed the $\mathrm{Au} 4 \mathrm{f}_{7 / 2}$ and $4 \mathrm{f}_{5 / 2}$ doublet typical for $\mathrm{Au}(0)$ (Table 2). The $\mathrm{Ag} 3 \mathrm{~d}_{3 / 2}$ and $\mathrm{Ag} 3 \mathrm{~d}_{5 / 2}$ peaks are indicative of a $\mathrm{Ag}(\mathrm{I})$ oxidation state and stand the same as those for CTASB. The $\mathrm{Br} 3 \mathrm{~d}_{5 / 2}$ binding energy for both gold nanorods samples is consistent with $\mathrm{Br} 3 \mathrm{~d}_{5 / 2}$ in the pure CTASB spectrum and not with that of a silver bromide sol. The N1s peak can be attributed to $\mathrm{N}^{+} .{ }^{23}$ Its binding energy at $402.45 \mathrm{eV}$ for both gold nanorod samples is slightly higher than that for pure CTASB due to the gold surface vicinity. In fact, the vicinity of nitrogen with silver mainly explains the shift in energy for CTASB and capped gold nanorods as compared with CTAB whose $\mathrm{N}^{+} 1$ s peak is at $\sim 402$ $\mathrm{eV}^{24}$ Therefore, CTASB appears to be the only species present on the surface of the gold nanorods. The $\mathrm{C} 1 \mathrm{~s}$ carbon peak for all samples was split into two contributions: one from the aliphatic carbons at $285 \mathrm{eV}$ and another from the supposedly $\mathrm{C}-\mathrm{N}$ ones at $286 \mathrm{eV}$. A Br/Ag ratio of 2 could be drawn from the XPS quantitative analysis of capped nanorods, with this value being in agreement with the chemical formula for CTASB. The XPS spectrum of gold nanospheres, synthesized without silver, was also taken. The binding energies for $\mathrm{C} 1 \mathrm{~s}, \mathrm{Au} 4 \mathrm{f}$, and $\mathrm{Br} 3 \mathrm{~d}$ present the same values as those for gold nanorods. However, the $\mathrm{N}^{+} 1 \mathrm{~s}$ peak is now at $402.15 \mathrm{eV}$. This value is slightly higher than that for pure $\mathrm{CTAB}$, indicative of the interaction between CTAB and the gold surface, but differs from the value for gold nanorods and CTASB. It thus confirms the capping of the gold nanorods by CTASB and not CTAB.

All these observations are indicative not only of an in situ formation of CTASB in the CTAB/silver nitrate synthesis but

(22) Eustis, S.; El-Sayed, M. A. J. Appl. Phys. 2006, 100, 0044324.

(23) Ichinose, I.; Kimizuka, N.; Kunitake, T. J. Phys. Chem. 1995, 99, 3736 3742 .

(24) Horr, T. J.; Arora, P. S.; Ralston, J.; Smart, R. S. C. Colloids Surf., A 1995, 102, 181-190 also of a stronger adsorption energy for CTASB than that for $\mathrm{CTAB}$, since after washing of the rods CTASB, though in lower concentration initially, as compared to $\mathrm{CTAB}$, is the only species to be detected via XPS as well as ${ }^{1} \mathrm{H}$ NMR spectroscopy. In order to understand this exclusion of CTAB from the gold surface, the separate adsorption of these two surfactants onto a bulk gold surface was measured by quartz crystal microbalance (QCM) experiments. The gold covered quartz crystal, purchased from Maxtek, was exposed to a $1 \mathrm{mM}$ CTASB solution and to a $1 \mathrm{mM}$ CTAB solution. The adsorption of $\mathrm{CTAB}(\mathrm{SB})$ onto the gold is measured in terms of the frequency shift of the QCM (Figure S5, Supporting Information). The adsorbed amount was calculated with the Sauerbrey equation. ${ }^{28}$ A total adsorbed mass of $150 \mathrm{ng}$ of CTAB and $340 \mathrm{ng}$ of CTASB was obtained, that is, 400 and $615 \mathrm{mmol}$, respectively, thus indicating that CTASB adsorbs around 1.5 more than $\mathrm{CTAB}$ onto a gold surface. As compared with previous QCM experiments led on several CTAX (X = $\left.\mathrm{NO}_{3}{ }^{-}, \mathrm{OH}^{-}, \mathrm{Cl}^{-}, \mathrm{Br}^{-}, \mathrm{I}^{-}\right)$surfactants ${ }^{16}$ where the maximum sorption on a gold surface was obtained with CTAB, CTASB appears to have an even increased adsorption to gold. It implies that when both CTAB (or another of the CTAX surfactants quoted above) and CTASB are present in the solution during the synthesis, the strong adsorption of CTASB implies a strong exclusion of CTAB or other CTAX surfactant from the gold surface and, all the more, that for each tested concentration the total amount of CTASB in solution is sufficient to cover the nanorod surface, even considering one CTASB molecule per gold surface atom. Further adsorption experiments were led on sputtered gold surfaces exposed to different surfactant solutions for $2 \mathrm{~h}$ and then thoroughly washed with water. The sputtered gold surfaces were then analyzed by XPS. Two groups could be observed. Gold surfaces exposed to a CTASB solution, CTAB/CTASB, or $\mathrm{CTAB} / \mathrm{AgNO}_{3}$ solutions with a CTAB concentration of $0.2 \mathrm{M}$ and silver concentrations of $1.92 \mathrm{mM}$ and $0.76 \mathrm{mM}$ presented the $\mathrm{C} 1 \mathrm{~s}, \mathrm{Ag} 3 \mathrm{~d}, \mathrm{~N} 1 \mathrm{~s}$, and $\mathrm{Br} 3 \mathrm{~d}$ binding energies already reported for CTASB and CTASB capped gold nanorods. A gold surface exposed to a $0.2 \mathrm{M} \mathrm{CTAB}$ silverless solution has its $\mathrm{N}$ 1s peak at the same position as the one for $\mathrm{CTAB}$ gold nanospheres. For surfaces exposed to solutions of CTAB/CTASB or $\mathrm{CTAB} / \mathrm{AgNO}_{3}$ with a CTAB concentration of $0.2 \mathrm{M}$ and a silver concentration of $0.48 \mathrm{mM}$, the $\mathrm{N} 1 \mathrm{~s}$ peak appears to be at an intermediary value, at $402.3 \mathrm{eV}$, indicative of a mixed surface covering of both CTAB and CTASB. In that case, the concentration of CTASB is too low to dominate the surface adsorption. In addition, the quantification shows that the adsorption of bromide as well as nitrogen is increased in the presence of CTASB or silver nitrate as compared to the adsorption where the surfactant solution solely contains CTAB. Calculated atomic ratios between adsorption in the presence $(0.76$ or $1.92 \mathrm{mM})$ and absence of silver are $\sim 1.8$ and 2.9 for nitrogen and bromide, respectively. The final curvature of the rod interface must be due to a subtle balance between a strong adsorption of CTASB which wants to stabilize this $\mathrm{Au}-\mathrm{CTASB}$ complex and the CTA chain association which promotes a directional growth effect.

The behavior of CTASB was studied by tensiometry, reporting it to have a surfactant behavior. However, no micelle formation could be detected, due to the CTASB low solubility limit in water (inferior to $1 \mathrm{mM}$ ). This limit explains why the synthesis cannot be led in a pure CTASB solution and has to make use

(25) Wagner, C. D. J. Vac. Sci. Technol. 1978, 15, 518-523.

(26) Wagner, C. D.; Moulder, J. F.; Davis, L. E.; Riggs, W. M. Handbook of $X$-ray photoelectron spectroscopy; Perking-Elmer Corporation, Physical Electronics Division: Eden Prairie, MN, 1979.

(27) Guzenko, A. F.; Yudin, A. L.; Yatsina, N. A.; Kolesnikov, L. V. High Energy Chem. 2005, 39, 318-323.

(28) Sauerbrey, G. Z. Phys. 1959, 155, 206. 
of CTAB as a cosurfactant. In addition to the demonstrated CTASB surface complexation, a possible scenario is thus that CTAB acts as a chemical stabilizing agent for gold salt, through the formation of $\mathrm{aCTA}^{+} \mathrm{AuBr}_{4}{ }^{-}$complex. In that case, it prevents a direct reduction in solution to metallic gold by ascorbic acid prior to $\mathrm{NaBH}_{4}$ addition. Further studies along this direction are in progress.

\section{Conclusion}

We have set up a new way of synthesis of gold nanorods with the use of a complex cosurfactant along with CTAB. Silver is now inserted in the solution through this complex form. Spectroscopic characterizations of the final products have evidenced the presence of the complex on the surface of the nanorods. Adsorption studies have confirmed the strong adsorption properties of CTASB on gold bulk surfaces and subsequently stressed its primordial role as a rod inducing agent.

Acknowledgment. The authors thank Jean-Marc Verbavatz for TEM characterization, Pascale Jegou for XPS analyses, and Aurélie Ithurbide for QCM measurements.

Supporting Information Available: NIR-visible, XPS, and ${ }^{1} \mathrm{H}$ NMR spectra of gold nanorods; XRD patterns of gold nanorods; and QCM adsorption measurements. This material is available free of charge via the Internet at http://pubs.acs.org.

LA801711Q 